Omodan, B.I., Tsotetsi, C.T. \& Ige, O.A. Managing the Culture of COVID-19 "New Normal" as a Motivation for University Students in South Africa

\title{
Managing the Culture of COVID-19 "New Normal" as a Motivation for University Students in South Africa
}

\author{
Bunmi Isaiah Omodan ${ }^{* 1}$, Cias T. Tsotetsi ${ }^{2}$ and Olugbenga A. Ige ${ }^{3}$ \\ *Corresponding Author: bomodan@wsu.ac.za \\ 1. Walter Sisulu University, Faculty of Education, South Africa. \\ 2. University of the Free State, School of Education Studies, South Africa. \\ 3. University of the Free State, School of Social Sciences and Language Education, South Africa. \\ Received : 2021-06-16 \\ Revised : 2021-07-31 \\ Accepted : 2021-08-17 \\ $10.46303 /$ ressat.2021.10
}

\begin{abstract}
How to cite this paper: Omodan, B.I., Tsotetsi, C.T. \& Ige, O.A. (2021). Managing the Culture of COVID-19 "New Normal" as a Motivation for University Students in South Africa. Research in Social Sciences and Technology, 6(2), 37-51. https://doi.org/10.46303/ressat.2021.10

This is an Open Access article distributed under the terms of the Creative Commons Attribution 4.0 International license (https://creativecommons.org/licenses/by/4.0/).
\end{abstract}

\section{Abstract}

The advent of COVID-19 and its implication on university education has been the bone of contention in recent times. The COVID-19 emergency has led to a change in knowledge inputs, processes, and outputs. This trajectory has demotivated student approaches to their learning. In response to this revolution, this study provides motivational strategies through students' perspectives to respond to the underside of new normal among South African university students. Ubuntu underpins the study within the Transformative Paradigm lens and Participatory Research as a research design. Ten students of a particular module in a selected university in South Africa were chosen to participate in the study. They were selected using the snowballing sampling technique because the participants were under level 3 lockdown with little or no access to campus at the time of the study. Online interview via phone calls, email and WhatsApp, was conducted with the students, and the data were analysed using Thematic Analysis. The study revealed a lack of visualised physical engagement between students and their lecturers and unstable internet access and lack of the internet as the major challenges. The study, therefore, recommends solutions that there should be adequate provision of effective online audio-visual sessions with enough space for student-lecturer's interactions and low-tech online sessions and content deliveries.

Keywords: Students' motivation, COVID-19, Internet-of-things, Online learning, Ubuntu. 
Omodan, B.I., Tsotetsi, C.T. \& Ige, O.A. Managing the Culture of COVID-19 "New Normal" as a Motivation for University Students in South Africa

\section{Introduction}

Coronavirus, otherwise called COVID-19, a very contagious and easy-to-spread pandemic, emanated from the Wuhan state of China in late 2019 becomes a global pandemic on March 11, 2020, as declared by World Health Organization (WHO, 2020; Shereen et al., 2020). The disease could be transmitted through human contact, which is not limited to handshaking, and other characteristics of human relationships (Liu et al., 2020), resulting in the change and adjustment into human socialisation and interaction in the quest to control the spread. WHO (2020) confirmed that the virus has spread to 213 countries globally, among which South Africa and other African countries are included. The effect of this COVID-19 and its preventive measures have affected many organisations' productivity, including the world's education system. The South Africa University system is not an exception. However, Weeden and Cornwall (2020) confirm that younger students seem to be at low risk compared to adults, but many universities, including South African universities, adhered to the World Health Organization measures such as social distancing in populated areas such as schools. Consequent to the implementation of social distancing, 46 countries, as of March 2020, shut down their schools nationwide, including South Africa (Huang et al., 2020; Jimola \& Ofodu, 2021; Jinadu et al., 2021).

The advent of COVID-19 and its implications on university education has recently been the bone of contention. This is not limited to its effects on the teaching and learning, management of the system, and the behavioural effect on both the students and their lecturers (Ching, 2020; Omodan, 2020a). This state has inevitably led to a change in knowledge inputs, processes, and outputs, and this unequivocally has led to a change in the way students' approach and address their lecturers. Students, at times, expect all teaching and learning processes to be made open without deadlines. Such behaviours emanating from the effect of COVID-19 new normal in our observation and experience, if not measured, could lead to disagreement, differences and disharmony in the university classrooms. In a bid to ameliorate this, there is a need to devise a motivational strategy through students' perspectives to respond to the underside of new normal in universities classrooms. Motivation has been found to be significant to students' academic performance (Goodman et al., 2011; Sivrikaya, 2019), and this is why the place of students' motivation during the COVID-19 online teaching and learning could not be underrated.

\section{The Importance of Students' Motivation during COVID-19 New Normal}

According to Tohidi and Jabbari (2011), motivation is the driving force that empowers people to overcome high-level performance barriers. Merriam-Webster (1997) defines motivation as a condition of motivating such as stimulus, driving force, influence, incentives, and drives that instigate action towards achievement. This is what Williams and Williams (2011) tagged as expenditure of effort to accomplish results. From the foregoing, it could be deduced that motivation is the driving force, instigator and persistence of human change in behaviour. However, student motivation could be viewed as what drives, instigates, influences, and stimulates students' academic performance. This is not far from Palmer's (2007) view that students' motivation is the fundamental element that propels quality education. From this definition, students' performance, which is the output of an educational organisation, is synonymous with quality education. Motivating students towards success during the 
Omodan, B.I., Tsotetsi, C.T. \& Ige, O.A. Managing the Culture of COVID-19 "New Normal" as a Motivation for University Students in South Africa

implementation of the "new normal" (online learning) is a great concern because the focus of the adjusted teaching-learning during the pandemic is for students to succeed in education. Therefore, the challenge here is how to get students motivated to enable them to cope with the new system, learn, and succeed independently. This is very significant to their academic performance and overall achievement (Elliot \& Dweck, 2005).

On the importance of students' motivation towards achievement and performance, research has suggested that a highly motivated individual is likely to be committed to the achievement of the organisational goals and objectives (Fakunle, 2016). This is to conclude that committed workers, despite all hurdles, are assets to the progress of the organisation. Similarly, highly motivated students tend to perform well and succeed in the school system (Ohadugha et al., 2020). Following the finding of Adamma et al. (2018), motivation improves students' academic performance with no variance in gender. Daniels et al. (2001) reported that when teachers are supportive, give feedback and caring translates to students' motivation towards their performance outcome. The characteristics of motivation, which include being supportive, giving feedback, and caring for students, are some of the leadership characteristics of a good teacher, which agrees with the finding of Adedigba and Sulaiman (2020) that there are positive relationships between leadership style and pupils' motivation towards their learning and academic performance.

From the foregoing, one could deduce that motivation goes a long way in ensuring students' academic achievement during the COVID-19 new normal. This cannot be achieved outside the university management style, the lecturer and the teaching and learning process, and students' involvement in the decision-making concerning their interest in implementing the new normal. This is to say that the process of implementing the new changes of COVID-19 must be allinclusive. This corroborated Omodan (2016) and Omodan (2019) view that students' involvement in making decisions regarding their lives reduces stress and possible conflict in the university system. To ensure that students are motivated and involved in the university decision to implement online learning during COVID-19, the place of Ubuntu as a philosophy of love, kindness, unity, and human consideration becomes relevant to theorise the study.

\section{Ubuntu as a theoretical framework}

Ubuntu was adopted as a theoretical framework for this study. Ubuntu is an Africanised way of life where people see themselves as "us" and not "I". This was described by Msengana (2006) as collective personhood of social morality. This was conceptualised in Xhosa proverb as "umntu ngumntu ngabantu" which could be interpreted as "I am because we are". That is, individual personhood is valid through others (Mbigi, 1997:2). From an etymological point of view, Ubuntu was coined from Xhosa words "ubu" which mean "being" and "ntu" which means "human" (Ramose, 1999). That is, Ubuntu simply means humanity (Tworeck, et al., 2015). Ubuntu involves love, compassion, togetherness, unity and oneness in diversity (Khomba, 2011; Omodan, 2020a). From these definitions, one could re-affirm that Ubuntu is a collective worldview that promotes love, oneness, and unity for collective success. In line with the interpretation of Msengana (2006) and Jolley (2011), Ubuntu preaches an adage of "my success is your success, my pain is your pain", social relatedness and well-being, leading to quality of life towards a common goal. In short, Ubuntu is a way of life where people live together as one and in oneness for the purpose of their development. However, Ubuntuism seems to be 
Omodan, B.I., Tsotetsi, C.T. \& Ige, O.A. Managing the Culture of COVID-19 "New Normal" as a Motivation for University Students in South Africa

applicable to people who share a common goal and objectives, such as the university community. This is supported by Tutu (1999) that Ubuntu strengthens people with common goals without separation or discrimination. Based on the above exploration, we argue that the Ubuntu-like university system during COVID-19 will enhance empathy, generosity, love and compassion to emancipate the disadvantaged (students) and help them succeed.

This theory is relevant to this study because one could view togetherness, love, compassion, humanism as a means by which students could be motivated to work well and see themselves as a reflection of the University and vis-à-vis. With Ubuntu in the wake of COVID-19 new normal, students' social and psychological needs are certain through collaboration, interdependence, and inclusivity in the system (Bolden, 2014; Omodan, 2020a). That is, the spirit of Ubuntu, when invoked by the University by ensuring that students get all the necessary supports to help them navigate the stress and huddles of the new normal, will motivate them for academic success. This is because social attachment motivation has been found to enhance students' achievement (Omodan \& Tsotetsi, 2018). Since Ubuntu is adjudged as a process that could ensure students' motivation in universities during COVID-19 new normal, the study, therefore, aimed to explore a motivational strategy to respond to the underside of "new normal" in university classrooms. To achieve this, the question of how universities should ensure that students are motivated was raised and answered.

\section{Research Question}

The following research question was raised to guide the process of providing solutions to the problem of the study;

- How can university students be motivated towards managing the culture of the new normal in South Africa?

\section{Research Objectives}

The study aimed to:

- explore students' challenges during the new normal implementation regarding the online teaching and learning.

- seek possible solutions from the students to the challenges arising from the implementation of the new normal online teaching and learning.

\section{Methodology}

\section{Research Paradigm and Design}

The study is situated within the Transformative Paradigm (TP) because of its focus on transforming students' predicament relating to their studies during COVID-19 new normal. TP is a form of research umbrella that seek to emancipate disadvantaged people (Omodan, 2020b). We considered this paradigm a lens for this study because of its quest for emancipation and post-modernism agitations toward bettering the status quo (Gunbayi, 2020). TP is relevant because it also ensures that research must be conducted so that the researched are recognised by making them co-producer of solutions to their problems (Mertens, 2010). This was implemented by making the students at the receiving end co-producers of the new knowledge. By doing so, we designed the study under the principles of Participatory Research (PR). PR is 
Omodan, B.I., Tsotetsi, C.T. \& Ige, O.A. Managing the Culture of COVID-19 "New Normal" as a Motivation for University Students in South Africa

used because it enables the researchers to implement the collaborative assumption of TP by involving the participants in the input, process and production stage of the research work. Our intention to involve the participants throughout the research is based on the opinion of Ruffa and Harrison (2020) that researchers in this design must ensure genuine participation of the people facing the problem as participants in the process of finding solutions their problem. To this end, the participants include the students who face the challenges of teaching and learning as a result of the change of system during the COVID-19. The selection and description of the participants are explained below.

\section{Participants and Selection Procedure}

The participants for the study were the students of a selected university in South Africa. The students were considered appropriate because they face the challenges coming from the implementation of online learning during COVID-19. The selected students were restricted to a particular general module for undergraduate studies with more than 200 students. One of the researchers is the module lecturer, who confirmed that the modules were taught only by using the online teaching-learning mode from the beginning to the end. Ten students were selected using the snowballing selection approach. This approach is appropriate to select the participants because, as at the time of the study, students were all working from home as universities in Africa, including the selected University, are using the online teaching-learning system. Having considered the possibility of getting hold of the students to participate in the study, we decided to adopt the snowballing selection approach. Snowballing is appropriate for us when there are difficulties in reaching the subjects that possess the expected characteristics, hence reaching only through referrers (Audemard, 2020). This method assists us in getting the needed students of the targeted modules.

\section{Instrumentation}

We used an online interview to collect data from the participants. This was adopted because the participants could not be reached face-to-face due to the COVID-19 lockdown that has caused all university activities to be done remotely. This was conducted using WhatsApp, Emails, and telephonic conversations with the participants. The interview with the participant was made to answer questions around what they found challenging during the implementation of the new normal, and secondly, on what they think will be okay to ameliorate the challenges. Fifteen students were informed and requested to join the research process, but only ten were willing to participate actively. However, collecting data online was a challenge because the participants mostly did not have data and were unwilling to spend extra time outside their already loaded online academic activities. The data collected were subjected to thematic analysis-as discussed below.

\section{Method of Data Analysis}

We adopted a Thematic Analysis (TA) to make sense of the collected data. TA is an established method of analysing qualitative data (Salleha et al., 2017). According to Nowell et al. (2017), this method enables researchers to identify, analyse, and report data based on themes. According to Braun \& Clarke (2006), the implementation of thematic analysis involves six steps: familiarisation with data, coding the data, assigning data into themes, reviewing the themes, defining and naming the themes and lastly produce reports thematically. However, we followed 
Omodan, B.I., Tsotetsi, C.T. \& Ige, O.A. Managing the Culture of COVID-19 "New Normal" as a Motivation for University Students in South Africa

the steps by reading and re-reading the data; we coded the data and categorised statements into themes with adequate reviews. The categorised data was defined and named with appropriate themes, and the report was produced below. During this research, we ensured that the issue of ethics was observed to protect both the researchers and the participants from any potential harm. This is important because it enables the researched community to have trust in the research process (Vanclay et al., 2013).

\section{Ethical Consideration}

To this end, we ensure that freedom for the participants to withdraw from the research process should they feel uncomfortable was granted to them. And we also ensured that their identities were protected by ensuring that their names did not surface in any aspect of the research process and the output. During the product stage, that is, analysis, their names were replaced with pseudo names: student 1 was named S1, student 2 was named S2, student 3 was named S3.... while student 10 was named S10. In this study, trustworthiness, which is equivalent to reliability and validity in quantitative studies (Mohajan, 2017) were ensure. The data collection process and the collected data were handled with an iota of trust and honesty to ensure quality, credibility, dependable and conformability and transferrable research output (Korstjens \& Moser, 2018). However, the study did not seek approval from any entity because the study was designed and conducted on the researchers' volition.

\section{Presentation of Findings}

In order to answer the research question of the study, the data was generated through the process of Transformative Paradigm (TP) with the use of Participatory Research (PR); we categorised the data in line with the principles of Thematic Analysis. This was done using the objectives of the study as bases for each theme and the sub-themes. The first objective of understanding the challenges facing students during the implementation of COVID-19 new normal generated two sub-themes: lack of visualised physical engagement, unstable internet access, and lack of internet of things. The second objective that seeks to provide solutions that could motivate students during the new normal, also came up with two themes: providing effective online audio-visual sessions and data minimisation in online lecturers. See the below table 1.

Table 1: Thematic representation of data based on the research question and objectives

Research Question: How can university students be motivated towards managing the culture of the new normal in South Africa?

\section{Objectives}

1. The study explores students' challenges during the new normal implementation regarding online teaching and learning.

2. The study also seeks possible solutions from the students to the challenges arising from the implementation of the new normal online teaching and learning.
Analysis of Sub-themes

1. Lack of Visualised physical Engagement.

2. Unstable internet access and lack internet of things.

3. Provision of effective online audio-visual session.

4. Provision of low-tech online lecturers. 
Omodan, B.I., Tsotetsi, C.T. \& Ige, O.A. Managing the Culture of COVID-19 "New Normal" as a Motivation for University Students in South Africa

Objective 1 theme 1: Lack of Visualised physical Engagement.

The changes that have befallen universities due to the COVID-19 pandemic have placed physical contact sessions on hold. This is because of the acute work-from-home syndrome that all universities must adhere to, respect and maintain the pandemic measures. This is not limited to implementing social distancing where everyone must stay away from one another and disallow physical contact, among others (Liu et al., 2020). This principle is also applicable in universities where all students engaged with their classes via the online teaching-learning system. However, this is not suitable for the students as the absence of physical contact in teaching and learning constitute a threat to their learning. See the below participants' statement:

S1: "E-learning tends to be challenging especially if it is not undertaken in conjunction with traditional classroom environment mainly because in faceto-face learning as students we are able to engage more and learn through visual presentations."

S4: "The struggle is real, but then I normally split my assignment pages and ask people to type for me with their computers; at the end, one will combine and submit; this would have been easy if we were physically present in the campus to assist ourselves".

S4: "the whole transition to digital learning is hard, the information is just too many to comprehend and even with the videos offered I feel like face to face sessions are needed for one to grasp the difficult material we have to get through"

S5: "It becomes hectic where I do not understand some concepts or assignment questions because there is no one to consult."

S6: "The consultation hours have been badly interrupted. Some of the things are better articulated and explain face-to-face."

From participant $\mathrm{S} 1$, the use of complete online learning is very challenging because it disallows social engagement with peers. According to this participant, even with the lecturers, this is linked to the fact that they are used to blended learning where both online and contact sessions are the process of teaching and learning. In the statement of participant S4, his assignment, which could have been done in collaboration with other students, is no more possible, and he ended up seeking the assistance of other students to complete such a task. The statement of S4 also corroborated that the new normal, that is, the transition from the traditional classroom to online learning and teaching, is hard because they could not comprehend. Even with the use of videos, the participant still believes that it could be better in face-to-face engagement. Maybe that is why the statement of S5 also suggests that online learning did not allow enough engagement that could allow students to comprehend issues because there is no avenue for a consultation where clarifications could be made. The statement of $\mathrm{S} 6$ also supports this that the consultation hours they are used to in the physical sessions has poorly been interrupted and no longer effective during the "new normal". Even the use of online learning seems to affect 
Omodan, B.I., Tsotetsi, C.T. \& Ige, O.A. Managing the Culture of COVID-19 "New Normal" as a Motivation for University Students in South Africa

adequate dissemination of information to the students. The bellow statements also shed more light:

S8: The online lectures, in my opinion, do not provide adequate information to understand the topic on like the face-to-face classes, in the online classes, we would raise hands to ask for clarity."

59: "The fact that we are given the guidance from our lecturers on face-to-face sessions, the online learning becomes hard to adapt."

S10: "The group discussions in between the face to face lectures were really helpful, and really assisting in picking up the pace when lost regarding what was said in class. Therefore, online lectures do not create that opportunity"

From the above statements, participant 88 lamented that the teaching mode is currently not as productive as the old ways of the face-to-face classroom because the online learning did not allow them to ask questions from the lecturers as they wish to do. From the statement of the S9, the students are used to the old ways where there is physical engagement and thereby do not allow them to adjust to the new normal quickly. From participant S10, the new ways of teaching and learning are not really helpful, like the old ways to get hold of the lecturer for clarification where there is a need to do so.

This analysis could confirm that the lack of physical engagement between the students and their lecturers resulted from lockdowns and social distancing a challenge. This is supported by Rosa's (2020) finding that students do not engage well with their studies during the COVID-19 new normal. The study found out that $45 \%$ of the San Antonio schools in the United States are less engaged with their studies, with revelations that $64 \%$ of parents also confirmed the same about their students during work-from-home teaching styles. This finding is consistent with Ali's (2020) finding that the system has subjected the students only to self-studies, which is not enough compared to the curriculum proposition.

Objective 1 theme 2: Unstable internet access and lack of internet of things

Another challenge that students face during COVID-19 online learning is unstable internet access and a lack of internet-enabled devices. This is consistent with the World Bank's prediction when considering the possible changes in the education system during the COVID19 pandemic. Most students have challenges accessing good internet, mostly those staying in the rurally located communities (World Bank, 2020). This experience is not far from the happening in the selected University in South Africa. The data confirms that inadequate data, low access to the internet and the internet of things are insufficient. See the bellow statements:

S2: "What did not work for me was having assessments so close to each other because it is a bit difficult to research the assessment because of lack of data and good internet access."

S4: "Furthermore, with the closing of internet Cafes it was challenging for me to complete the tasks or assignments due to having no Personal Computer as I used to use the one provided by the school which they collected when we closed." 
Omodan, B.I., Tsotetsi, C.T. \& Ige, O.A. Managing the Culture of COVID-19 "New Normal" as a Motivation for University Students in South Africa

S3: "downloading online video clips from Blackboard was not a big issue, the problem is that some of us do not have computers we have to use our phones and only to find that that video needs so much space to be downloaded, and it was a problem."

S6: "And the biggest problem for me is with the network coverage in my area. We would go for 5 hours without internet, which is affecting the quality of my work".

Participant S2 lamented that it was difficult to complete or do research because of the lack of data and uninterrupted internet access from the above participants' statements. This is to say that the internet being the only means to implement online learning, is not equally available to students in the same quantity. Participant S4 further reiterates that the lack of a personal computer is an issue, and it does not allow him to come up with his work as and due. The lockdowns and social distancing policy also affect the public internet Café, which did not allow him to use such Café as an alternative. The lack of a computer also suffixed in the statement of participant S3, which makes them resulted in the use of Mobile Phones, but unfortunately, phones could not perform like a computer. The issue of devices and the lack of internet to make use of the available devices is also an issue as lamented by participant S6. The problem of slow internet also compounds the challenges as stated in the below statements:

S7: "online classes did not really work for me because I live in a small town where sometimes the network is slow, and it takes time to process, so I always missed those online lectures, even though I tried to open the link thirty minutes before I still struggled so that was a huge challenge and it is unfortunate for me to miss out a class".

59: "This is a major problem for me as a student because whenever the electricity goes, there is a problem with an internet connection, and that makes it difficult to finish my work on time."

S10: "What did not work for me is the fact that we are only given a single attempt to do online quizzes, and we are currently facing electricity problems, and the network is connected with electricity. It might happen that we are busy with an online quiz, and there is a power-cut-of, and the network is lost".

The statement from participant S7 confirms that students living in rural communities are likely to have stable internet issues. This, according to S7, gives her a challenge to attempts her online task, even caused her to miss some classes. The statement from participant $\$ 9$ also confirms that they faced with the issue of unstable internet. This, according to S9, is when there is no electricity supply automatically leads to cut-off internet and thereby affect whatever academic activities take place at that time. The statement of S10 also reiterates that the problem of unstable electricity is rampant and thereby affect the availability of the internet, which also hinders student most especially when attending to an online quiz.

This analysis found that unstable internet access and lack of the internet of things is one of the major challenges that students face during the implementation of online learning in university classrooms. This is consistent with Ali (2020) findings that students lack the necessary ICT 
Omodan, B.I., Tsotetsi, C.T. \& Ige, O.A. Managing the Culture of COVID-19 "New Normal" as a Motivation for University Students in South Africa

infrastructures with a recommendation that staff and students' need to be in possession of the internet of things, learning applications, and learning platforms. This finding also confirmed World Bank's argument that all institutions must be aware that the physical classroom content may not be easy to be reformed into an online platform. Therefore, "interaction models, assessment, content, pacing, and instructional approaches may all need to be adapted when transitioning to online learning" (World Bank, 2020).

\section{Objective 2 theme 3: Provision of effective online audio-visual session}

Based on objective number two seeks to provide solutions to the students' challenges during COVID-19 new normal. Among the solutions suggested by the students being researched is that there is a need for an effective online platform that will enhance both audio and visual classes. The postulation of this solution reflected in the participants' statements below;

S1: "Should it happen that we do not go back to traditional learning soon, then we should continue with PowerPoint presentation with voice over, and for engaging purpose, I think the lecturer could assist by creating Microsoft teams for video conferencing so that we can interact effectively just like in a traditional classroom."

S4: The last session I missed because I got the email late, so prior notice should be made, and a full-on class session should be held whereby one can ask questions they seek clarity on. Such sessions should be held to teach and not only to clarify matters."

S5: "We can use an online platform such as in this module where a timetable and link has been sent to us of when we will have contact sessions and at what time. This way, we will be able to ask questions while the lecturer is going through the PowerPoint slides with us."

S6: "I believe if our lecturers can implement a strategy where we can have a link that will allow us to ask questions while the session is continuing. That will allow engagement and interaction."

The above statements confirm that if this online learning system continues, the students would be motivated if the system ensures means of passing across to students PowerPoint presentation that contain audible voice and visual demonstration of the lecturers. This, according to participant S1, will enhance good interaction between the lecturers and the students. This issue of the interactive session that will allow students to ask a question and engage the lecturers was also mentioned by participant S4. Such a session should be organised to teach and not only to clarify issues. The statement of participant S5 also recommends that the way the session in the selected module is conducted is a good example that is needed to happen across all modules. Lessons were conducted in the selected module using voice and video over PowerPoint slides and share with the students. This enables them to go back to the slides when they choose to study and re-study it again. However, the module also used Blackboard video classes where interaction is made possible. That is while S5 recommend that it will be good if the session is made in such a way to allow question and answer sessions. The statement of participants $\mathrm{S} 6$ also hopes for a strategy that could allow the student to interact 
Omodan, B.I., Tsotetsi, C.T. \& Ige, O.A. Managing the Culture of COVID-19 "New Normal" as a Motivation for University Students in South Africa

virtually with the lecturer. This confirms that there is a need for online teaching-learning that incorporates audio and video and interactive sessions. The below statements also confirmed that such a strategy would encourage students;

S8: lecturers need to encourage active learning, the way in which he/she facilitate discussions and show interest in all answers and redirect and guide the wrong answer towards the correct one will motivate us".

S10: "The only suggestion would be that the presentation of that session should be made available on the Blackboard so that we can look back at what we did in that session. During the lessons, we discuss the different topics, and I think that helps a lot on reflecting while in the class".

From the above statements, participant S8 confirmed that when lecturers conduct their sessions to enable question and answer with a willingness to respond to all queries, it will motivate them to attend their sessions. On the same request, the statement from participant S10 also requested that their sessions be recorded on Blackboard to enable them to have access to it at any time of their choice. This will allow them to reflect on their sessions at a later time. This is to confirm that one of the means by which students could be motivated is when online sessions are conducted to enable audio and videos presentations where students will have opportunities to engage and interact meaningfully with their lecturers. This is consistent with the finding of Heller, Calderon and Medrich (2003) that meaningful students' engagement is significant to students' academic success, while students' success is a point of motivation for students to study more (Stephens, 2015).

Objective 2 theme 4: Provision of low-tech online lecturers.

In order to implement the complete online learning, because all students came from different socio-economic backgrounds, that is, there are not equal when it comes to affordability of the internet of things. Students living in rurally located communities lack access and financial recourse to equip themselves with adequate internet of things during COVID-19 new normal (Seretse, Chukwuere, Lubbe, and Klopper, 2018). Thus, the students recommend solutions such as providing devices and other online communication with low consumptions of internet usage. The below statement shed more light on the need;

S3: "suggest that lesson delivery be made in the form of notes, slides or any other document. This is because videos consume so much space and some of us struggle to download them, especially if we do not have a personal computer. Or at least this can be provided in both ways so that those who cannot download videos at least they can read the provided notes."

S5: we need enough data because each uploaded video consumes large amounts of that, and some 'online' sessions are not convenient for everyone due to various socio-economic factors, and as a result, we missed lectures."

S10: "For me, there is a need for students to have computers and internet, I had no learning online because I find it hard to transition into this new method of learning because I am used to traditional lectures, but if there are enough resources with devices that will not consume too much data, it will be fine." 
Omodan, B.I., Tsotetsi, C.T. \& Ige, O.A. Managing the Culture of COVID-19 "New Normal" as a Motivation for University Students in South Africa

From the statements above, one could validate the fact that there is a need for the universities to ensure that the mode of lecture delivery should be done to reduce consumption of the internet. Participant S3 suggested that lessons should be made via notes, slides, and any other lighter means. This was requested because some of the students do not have the resources to acquire enough data to download heavy teaching materials online. The statement of participant S5 also confirmed that enough data is needed because to download video materials that consume a large amount of internet. And because many of the students come from a poor background with little money to buy enough internet, as a result of this, many students miss their online classes.

Participant S10 also lamented that he had no computer and internet to engage with his online learning, and a result request that internet and computer should be provided, most especially the ones that will not consume more internet. From this analysis, one could deduce that there is a need for the University to devise a means to conduct its lesion using the low-tech option. This will enable students to spend little or no internet while engaging in academic work online. This could stand as a motivation to attend online sessions since motivation has been proved to be a driving force, hence when students will not have to spend a lot to attend their academic works could enhance their willingness to be punctual (Tohidi \& Jabbari, 2011).

\section{Conclusion and Recommendations}

The study revealed that lack of visualised physical engagement between students and their lecturers, unstable internet access, and lack of internet of things are significant challenges facing university students during lockdowns that necessitated online teaching and learning. This may be regarded as anti-Ubuntu; these challenges among the learners do not depict the principle of love, compassion, unity for organisational success where all stakeholders of the universities see themselves as partners in the road to the road to success. We also found that the better ways to motivate students to take hold of their studies during COVID-19 new normal are the adequate provision of effective online audio-visual sessions and the provision of lowtech online sessions. These findings are consistent with the proposition of Ubuntu as a compassionate, collaborative and inclusive platform to which the University could ensure students motivation. Based on the suggested solutions, we recommend that university students be motivated by providing them with adequate provision of effective online audiovisual sessions with enough space for student-lecturers interactions and provision of low-tech online sessions and content deliveries.

\section{References}

Adamma, O. N., Ekwutosim, O. P. \& Unamba, E. C. (2018). Influence of Extrinsic and Intrinsic Motivation on Pupils Academic Performance in Mathematics. Supremum Journal of Mathematics Education, 2(1), 52-59. https://doi.org/10.5281/zenodo.1405857

Adedigba, O., \& Sulaiman, F. R. (2020). Influence of teachers' classroom management style on pupils' motivation for learning and academic achievement in Kwara State. International Journal of Educational Methodology, 6(2), 471-480.

https://doi.org/10.12973/ijem.6.2.471 
Omodan, B.I., Tsotetsi, C.T. \& Ige, O.A. Managing the Culture of COVID-19 "New Normal" as a Motivation for University Students in South Africa

Ali, W. (2020). Online and Remote Learning in Higher Education Institutes: A Necessity in light of COVID 19 Pandemic. Higher Education Studies, 10(3), 16-25.

https://doi.org/10.5539/hes.v10n3p16

Audemard, J. (2020). Objectifying Contextual Effects. The Use of Snowball Sampling in Political Sociology. Bulletin de Methodologie Sociologique, 145, 30-60. https://doi.org/10.1177/0759106319888703

Bolden, R. (2014). Ubuntu. In David Coghlan and Mary Brydon-Miller (Eds.). Encyclopedia of Action Research. London: Sage Publications. http://dx.doi.org/10.4135/9781446294406

Braun, V., \& Clarke, V. (2006). Using thematic analysis in psychology. Qualitative research in psychology, 3(2), 77-101.

Ching, G. (2020). From Face-to-Face to Blended Learning: Teaching and Learning during COVID-19 in Taiwan. SITE Interactive Online 2020 Conference-October 26-28, 2020.

Daniels, D.H., Kalkman, D.L. \& Mc Combs, B.L. (2001) Young children's perspectives on learning and teacher practices in different classroom contexts: implications for motivation. Early Education \& Development, 12(2), 253-273.

Elliot, A.J., \& Dweck, C.S. (2005). Handbook of competence and motivation. New York: Guilford Press.

Fakunle, F. A. (2016). Influence of Job Satisfaction on Job Performance among Academic Staff of tertiary Institutions in Ekiti State. M. Ed Thesis, University of Ado Ekiti. Nigeria.

Goodman, S., Jaffer, T., Keresztesi, M., Mamdani, F., Mokgatle, D., Musariri, M., Pires, J., \& Schlechter, A. (2011). An Investigation of the Relationship between Students' Motivation and Academic Performance as Mediated by Effort. South African Journal of Psychology, 41(3), 373-385. https://doi.org/10.1177/008124631104100311

Gunbayi, I. (2020). Knowledge-constitutive interests and social paradigms in guiding mixed methods research (MMR). Journal of Mixed Methods Studies, 1(1), 41-53.

Heller, R., Calderon, S., \& Medrich, E. (2003). Academic achievement in the middle grades: What does research tell us? A review of the literature. Atlanta, GA: Southern Regional Education Board.

Huang, R., Liu, D., Tlili, A., Yang, J., \& Wang, H. (2020). Handbook on Facilitating Flexible Learning During Educational Disruption: The Chinese Experience in Maintaining Undisrupted Learning in COVID-19 Outbreak. Beijing: Smart Learning Institute of Beijing Normal University.

Jimola, F. E., \& Ofodu, G. O. (2021). Sustaining learning during COVID-19 Seismic Shift: The Need to Develop Flexible Pedagogy. Interdisciplinary Journal of Education Research, 3(1), 13-26. https://doi.org/10.51986/ijer-2021.vol3.01.02

Jinadu, A. T., Oyaremi, M. K., \& Rufai, M. D. (2021). Assessment of the Oyo State Teaching Service Commission Interactive Learning Platforms during COVID-19 Lockdown in Nigeria. Interdisciplinary Journal of Education Research, 3(1), 37-44.

https://doi.org/10.51986/ijer-2021.vol3.01.04

Jolley, D. R. (2011). Ubuntu: A Person is a Person Through other Persons. Master's Degree. Southern Utah University. https://www.suu.edu/hss/comm/masters/capstone/thesis/jolley-d.pdf. 01/014/2020 Khomba, K. J. (2011). Redesigning the balance scorecard model: An African Perspective. Ph.D Thesis, University of Pretoria, South Africa. 
Omodan, B.I., Tsotetsi, C.T. \& Ige, O.A. Managing the Culture of COVID-19 "New Normal" as a Motivation for University Students in South Africa

Korstjens, I. \& Moser, A. (2018) Series: Practical guidance to qualitative research. Part 4:

Trustworthiness and publishing, European Journal of General Practice, 24:1, 120-124. https://doi.org/10.1080/13814788.2017.1375092

Liu, P., Beeler, P., \& Chakrabarty, R. K. (2020). Dynamic interplay between social distancing duration and intensity in reducing COVID-19 US hospitalisations: A "law of diminishing returns" < ? A3B2 show [editpick]?>. Chaos: An Interdisciplinary Journal of Nonlinear Science, 30(7), 071102. https://doi.org/10.1063/5.0013871

Mbigi, L. (1997). Ubuntu, the African Dream in Management. Randburg, Knowledge Resources.

Merriam-Webster (1997). Merriam-Webster's Dictionary. Houghton-Mifflin

Mertens, D.M. (2010). Philosophy in mixed methods teaching: The transformative paradigm as illustration. International Journal of Multiple Research Approaches, 4, 9-18.

Mohajan, H. K. (2017). Two Criteria for Good Measurements in Research: Validity and Reliability. Annals of Spiru Haret University, 17(3): 58-82. https://mpra.ub.unimuenchen.de/83458/

Msengana, N. W. (2006). The significance of the concept of 'Ubuntu' for educational management and leadership during democratic transformation in South Africa. PhD Thesis, University of Stellenbosch.

Nowell, L. S., Norris, J. M., White, D. E., \& Moules, N. J. (2017). Thematic Analysis: Striving to Meet the Trustworthiness Criteria. International Journal of Qualitative Methods. https://doi.org/10.1177/1609406917733847

Ohadugha, R. O., Chukwuemeka, E. J., Babatunde, A. E. (2020). Impact of Peer-mediated Learning on Achievement and Motivation in Computer Science among Senior Secondary School Students in Minna Metropolis, Niger State. Contemporary Educational Technology, 12(1), ep263. https://doi.org/10.30935/cedtech/7629

Omodan, B. I. (2016). Influence of Trade Unionism on Management of Tertiary Institutions in Ekiti State. M.Ed. Thesis, Ekiti State University, Ado Ekiti, Nigeria.

Omodan, B. I. (2019). A strategy to enhance crisis management between students and university authorities in Nigeria. PhD thesis, University of the Free State, South Africa.

Omodan, B. I. \& Tsotetsi, C. T. (2018). Student-Teacher Relationships as Panacea for Students' Academic Performance in Nigeria Secondary Schools: An Attachment Perspective. Journal of Social Studies Education Research, 9(4), 82-101. https://files.eric.ed.gov/fulltext/EJ1199100.pdf

Omodan, B. I. (2020a). Managing the Psycho-Social Vacuum of COVID-19 among Rural Learners through Ubuntu. Journal of Educational and Social Research, 10(6), 266-278. https://doi.org/10.36941/jesr-2020-0125

Omodan, B. I. (2020b). The Vindication of Decoloniality and the Reality of COVID-19 as an Emergency of Unknown in Rural Universities. International Journal of Sociology of Education. 20, 1-26. http://doi.org/10.17583/rise.2020.5495

Palmer, D. (2007). What Is the Best Way to Motivate Students in Science? Teaching ScienceThe Journal of the Australian Science Teachers Association, 53(1), 38-42.

Ramose, M. B. (1999). African philosophy through Ubuntu. Harare: Mond Books. 
Omodan, B.I., Tsotetsi, C.T. \& Ige, O.A. Managing the Culture of COVID-19 "New Normal" as a Motivation for University Students in South Africa

Rosa, S. D. (2020). Student engagement remains a challenge in distance learning. https://www.k12dive.com/news/student-engagement-remains-a-challenge-indistancelearning/584793/

Ruffa, S. C. \& Harrison, K. (2020). "Ask Me What I Want": Community-based participatory research to explore transition-age foster Youth's use of support services. Children and Youth Services Review. 108, 1-9. https://doi.org/10.1016/j.childyouth.2019.104608

Salleha, I. S., Alia, N. S. M., Mohd-Yusof, K. \& Jamaluddin, H. (2017). Analysing Qualitative Data Systematically using Thematic Analysis for Deodoriser Troubleshooting in Palm Oil Refining. Chemical Engineering Transactions, 56, 1315-1320. https://doi.org/10.3303/CET1756220

Seretse, M., Chukwuere, J., Lubbe, S. \& Klopper, R. (2018). Problems around Accessing Information in Rural Communities. Alternation, 25(1), 214-244. https://doi.org/10.29086/2519-5476/2018/v25n1a10

Shereen, M. A., Khan, S., Kazmi, A., Bashir, N. \& Siddique, R. (2020). COVID-19 infection: Origin, transmission, and characteristics of human coronaviruses. Journal of Advanced Research, 24, 91-98. https://doi.org/10.1016/j.jare.2020.03.005

Sivrikaya, A. H. (2019). The Relationship between Academic Motivation and Academic Achievement of the Students. Asian Journal of Education and Training, 5(2), 309-315.

Stephens, T. L. (2015). Encouraging Positive Student Engagement and Motivation: Tips for Teachers. Pearson, https://www.pearsoned.com/encouraging-positive-studentengagement-and-motivation-tips-for-teachers/

Tohidi, H., \& Jabbari, M. M. (2012). The effects of motivation in education. Procedia-Social and Behavioral Sciences, 31, 820-824.

Tutu, D. (1999). No future without forgiveness. London: Rider.

Tworeck, C., Hemminga, D., Huber, D. \& Dhillon, D. (2015). The Ubuntu philosophy as a management Strategy.

file:///C:/Users/bolab/Downloads/UbuntuasaManagementStrategy.pdf. 01/14/2020.

Vanclay, F., Baines, J. T. \& Taylor, C. N. (2013). Principles for ethical research involving humans: ethical professional practice in impact assessment. Impact Assessment and Project Appraisal, 31(4), 243-253. https://doi.org/10.1080/14615517.2013.850307

Weeden, K. A., \& Cornwell, B. (2020, May 30). The Small World Network of College Classes: Implications for Epidemic Spread on a University Campus.

https://doi.org/10.15195/v7.a9

WHO. (2020). Coronavirus disease (COVID-19) pandemic. 2020, from https://www.who.int/

Williams, K. C., \& Williams, C. C. (2011). Five key ingredients for improving student motivation. Research in Higher Education Journal, 12, 1-23.

World Bank. (2020). Remote Learning and COVID-19 The use of educational technologies at scale across an education system as a result of massive school closings in response to the COVID-19 pandemic to enable distance education and online learning. Retrieved from file:///E:/PC/Rapid-Response-Briefing-Note-Remote-Learning-and-COVID-19Outbreak.pdf 